Conclusions Despite improvements in neonatal care and increased survival, CP incidence has not changed over a period of 22 years, but its quality and severity have changed.

\section{PO-0445 NEUROBEHAVIORAL ASSESSMENT OF LATE PRETERM AND FULL-TERM INFANTS: A PRELIMINARY STUDY}

$\underline{P}$ Borges Nery, JS Camelo Júnior. Pediatrics, School of Medicine of Ribeirão Preto, Ribeirão Preto São Paulo, Brazil

10.1136/archdischild-2014-307384.1087

Neonatal neurobehavioral examinations describe newborn's behavioural repertoire and observable responses to environmental stimulus.

This study aimed to evaluate the neurobehavioral of healthy late preterm and full-term infants using Neonatal Neurobehavioral Assessment Preterm Infant (NAPI). We hypothesised that NAPI can detect neurobehavioral differences between healthy late preterm and full-term infant.

In this prospective cross-sectional study, infants born with 36 weeks gestational age (GA) (6 days) and 37 weeks GA (6 days) in a tertiary health care institution of São Paulo state, Brazil were assessed $24 \mathrm{~h}$ after birth, using NAPI. Newborns with malformations, genetics syndromes, neurological impairment, infections and ventilation assistance were excluded. NAPI was conducted only by one expert examiner, in the same place, and always one hour before feeding. The study was approved by the Ethics Committee and all mothers assigned the informed consent form. For the preliminary analysis was considered $\mathrm{p} \leq 0,05$.

Twenty babies (age: 36,5 \pm 0,6; birth weight: 2,764 \pm 558,16; gender: $70 \%$ male and 30\% female) had the scores compared by age (36/37 weeks GA) not showing significantly difference: scarf sign $(\mathrm{p}=0,685)$, motor and vigour development $(\mathrm{p}=0,758)$, popliteal angle $(\mathrm{p}=0,712)$, alertness and orientation $(p=0,939)$, irritability $(0,816)$, cry quality $(p=0,669)$ and percent asleep $(p=0,248)$. In this preliminary study we verified that neurobehavioral performances are similar, suggesting that for this population NAPI is not sensitive to detect subtle changes. However, more patients need to be included to confirm our findings.

\section{PO-0446 PARENTERAL NUTRITION COMPROMISES NEURODEVELOPMENT OF PRETERM PIGS}

${ }^{1}$ RK Buddington, ${ }^{2} \mathrm{~A}$ Choudhri, ${ }^{3} \mathrm{HJ}$ Sable, ${ }^{4} \mathrm{~V}$ Chizihikov, ${ }^{5} \mathrm{KK}$ Buddington. ${ }^{1} \mathrm{Health}$ and Sport Science, University of Memphis, Memphis, USA; ${ }^{2}$ Radiology, University of Tennessee Health Science Center, Memphis, USA; ${ }^{3}$ Psychology, University of Memphis, Memphis, USA; ${ }^{4}$ Anatomy and Neurobiology, University of Tennessee Health Science Center, Memphis, USA; ${ }^{5}$ Animal Care, University of Memphis, Memphis, USA

\subsection{6/archdischild-2014-307384.1088}

Background and aims Advances in neonatal intensive care and nutrition support have increased survival of preterm infants, but the risk of compromised neurodevelopment is a concern. We evaluated parenteral nutrition $(\mathrm{PN})$ as a heretofore unreported contributing factor to compromised neurodevelopment after preterm birth.

Methods Neurodevelopment of preterm pigs delivered at $92 \%$ of gestation (representative of 32 week preterm infants) and provided $\mathrm{PN}$ or enteral nutrition (EN) for 10 days was assessed by observations of motor activity, sensory and cognitive skills, brain mass, magnetic resonance imaging, and cerebellar histology. Fluid volumes, energy, and nutrients were comparable.

Results PN pigs grew slightly better than EN pigs, but had smaller brains $(28+0.5$ vs $32+0.6 ; \mathrm{p}=0.009)$, including the cerebellum, reduced motor activity $(\mathrm{p}=0.005)$ and sensory responses $(\mathrm{p}<0.05)$ that corresponded with underdeveloped myelination $(\mathrm{p}=0.004)$ from diffusion tensor imaging. PN was associated with lower serum lipids (triglycerides, $\mathrm{p}=0.05$; total cholesterol, $\mathrm{p}=0.04 ; \mathrm{VLDL}, \mathrm{p}=0.04 ; \mathrm{HDL}, \mathrm{p}=0.03$; and LDL, $\mathrm{p}=0.09$ ). Differences were also detected between PN and EN for weights of the kidneys, heart, pancreas, and spleen, but not lungs.

Conclusions $\mathrm{PN}$ is essential for many preterm infant, and particularly those delivered earlier in gestation. The neurodevelopment delay caused by total PN independent of confounding variables (disease, inconsistent gestational ages, diverse genetics, different nutritional support and NICU protocols) is a novel and disturbing finding. The preterm pig is a translational animal model for investigating the relationship between nutrition support and neurodevelopment after preterm birth, improving PN solutions, and advancing neonatal intensive care.

\section{PO-447 WITHDRAWN}

\section{PO-0448 CLINICAL AND ELECTROENCEPHALOGRAPHIC CHARACTERISTICS OF NEWBORN INFANTS WITH MILD HYPOXIC-ISCHAEMIC ENCEPHALOPATHY (HIE)}

M Camprubí, MS León, A Alarcón Allen, G Arca-Diaz, T Agut, A Garcia-Alix. Neonatology, Agrupació Sanitaria Clínic-Sant Joan de Déu, Barcelona, Spain

\subsection{6/archdischild-2014-307384.1089}

Background Neonates presenting with mild HIE within the first $6 \mathrm{~h}$ of life have not been included in therapeutic hypothermia trials. Consequently, aEEG, biochemical features and their temporal course are ill-defined. Our objective was to examine clinical and aEEG characteristics of neonates with perinatal HIE and mild initial encephalopathy.

Methods Prospective study including term neonates with HIE admitted in our centre January 2009-July 2011. Staging of encephalopathy was done before $6 \mathrm{~h}$ of age according to our validated scoring system. Clinical, aEEG and biochemical findings during the first 72 of infants with mild HIE were reviewed.

Results 55 patients were included, 12 of which were categorised as mild HIE: normal alertness but with altered tone or hyper excitability. All patients underwent aEEG monitoring during a mean time of $41.4 \pm 25 \mathrm{~h}$ and starting at $2.5 \pm 2.1 \mathrm{~h}$. Temporal evolution of tracings $(\mathrm{T})$ is described:

0 : no recording; 1: continuous normal voltage with sleepwake cycling (SWC); 2: continuous normal voltage without SWC.

\begin{tabular}{llllllll}
\multicolumn{7}{l}{ Abstract P0-0448 Table 1 } \\
\hline T3 h & T6 h & T9 h & T12 h & T18 h & T24 h & T36 h & T48 h \\
$0: 41.2 \%$ & $0: 33.3 \%$ & $0: 33.3 \%$ & $0: 33.3 \%$ & $0: 50 \%$ & $0: 58 \%$ & $0: 75 \%$ & $0: 83.3 \%$ \\
$1: 58.3 \%$ & $1: 66.7 \%$ & $1: 66.7 \%$ & $1: 66.7 \%$ & $1: 50 \%$ & $1: 42 \%$ & $1: 25 \%$ & $1: 16.7 \%$ \\
\hline
\end{tabular}


Clinical or electrical seizures were not present during the first $72 \mathrm{~h}$ nor the staging of HIE increased during this period in any of the patients. Mean CSF NSE at $72 \mathrm{~h}$ was $26 \mathrm{ng} / \mathrm{mL}(+/-7.8)$. Conclusions Clinical status of infants with mild HIE at $6 \mathrm{~h}$ of age does not worsen in the following $72 \mathrm{~h}$. The aEEG traces are consistently normal and subclinical seizures are uncommon.

\section{PO-0449 CORRELATION BETWEEN AMPLITUDE INTEGRATED EEG (AEEG) AND CLINICAL EVALUATION IN NEWBORN INFANTS WITH HYPOXIC-ISCHAEMIC ENCEPHALOPATHY (HIE)}

M Camprubí, A Alarcón Allen, G Arca-Diaz, MS León, T Agut, A Garcia-Alix. Neonatology, Agrupació Sanitaria Clínic-Sant Joan de Déu, Barcelona, Spain

\subsection{6/archdischild-2014-307384.1090}

Background and aims Both clinical staging and aEEG during the first $6 \mathrm{~h}$ correlate with outcome in neonates with HIE and are used for inclusion of patients in therapeutic hypothermia (TH) trials and clinical protocols. However, little is known about the correlation between clinical evaluation and aEEG tracing these infants.

Objective To determine the correlation between clinical evaluation and aEEG during the first $6 \mathrm{~h}$ of life in HIE infants.

Methods Prospective observational study of HIE infants admitted in a tertiary unit during 2009 to 2011 . A single clinician performed clinical exam before cooling indication. Staging of encephalopathy was done according to a validated scoring system. aEEG recording was performed from admission. Pattern classification was ranked from 1 to 5 (with higher scores indicating more suppressed traces).

Results 55 patients were included; $21.9 \%$ had mild, $27.3 \%$ moderate and $50.9 \%$ severe encephalopathy. The mean duration of a EEG recording was $71.52 \pm 34.6 \mathrm{~h}$ and aEEG started at a mean age of $4.3 \pm 3.1 \mathrm{~h}$. We found a correlation between aEEG and the following items: ability to awaken (AA) $(r=0.72)$, spontaneous movements $(r=0.73)$ and posture $(r=0.74)$. No correlation was observed between aEEG and myotatic reflexes $(\mathrm{r}$ $=0.44)$ and breathing pattern $(r=0.37)$. AA correlated with HIE stage $(r=0.85)$. Further, HIE stage correlated with the score of aEEG tracing at admission $(\mathrm{r}=0.77)$.

Conclusion aEEG tracing correlates well with the degree of altered alertness and with the clinical grading of HIE, supporting the validity of this tool to reflect the severity of brain dysfunction before cooling in infants with HIE.

\section{PO-0450 CORRELATION BETWEEN EARLY CEREBRAL FUNCTION MONITORING (CFM) AND CSF NEURON-SPECIFIC ENOLASE (NSE) IN NEONATES WITH HYPOXIC ISCHAEMIC ENCEPHALOPATHY (HIE)}

M Camprubí, A Alarcón Allen, MS Leon, G Arca-Díaz, T Agut, A Valls, A Garcia-Alix. Neonatology, Agrupació Sanitaria Clínic-Sant Joan de Déu, Barcelona, Spain

\subsection{6/archdischild-2014-307384.1091}

Background and aims aEEG predicts outcome in newborns with HIE. CSF-NSE serves as surrogate for HI brain injury. Little is known about the correlation between early aEEG and CSF-NSE within the first $72 \mathrm{~h}$ of age.

\begin{tabular}{|c|c|c|c|c|}
\hline & Total HIE N=55 & $\begin{array}{l}\text { Mild HIE } \\
(\mathrm{N}=12) 21.8 \%\end{array}$ & $\begin{array}{l}\text { Moderate HIE } \\
(\mathrm{N}=15) 27.3 \%\end{array}$ & $\begin{array}{l}\text { Severe HIE } \\
(\mathrm{N}=28) 50.9 \%\end{array}$ \\
\hline Outborn\% & $66.1 \%$ & $16.7 \%$ & $73.3 \%$ & $85.7 \%$ \\
\hline Weight (g), mean (SD) & $3035(580)$ & $3056(505)$ & $3075(554)$ & 2994(584) \\
\hline Death & $33.9 \%$ & $0 \%$ & $6.7 \%$ & $64.3 \%$ \\
\hline
\end{tabular}

Aim To examine the correlation between early aEEG and CSF NSE concentrations in neonates with HIE.

Methods Prospective observational study of term infants with HIE admitted at Agrupació Sanitaria Sant Joan de Déu-Clinic from 2009 through 2011. HIE was clinically graded according to a validated system. Patients with significant HIE underwent therapeutic hypothermia. CFM was performed in all cases. Pattern classification was ranked from 1 to 5 (with higher scores indicating more suppressed traces). The worst CFM tracing within the first $6 \mathrm{~h}$ and 6 to $12 \mathrm{~h}$ was correlated with CSF NSE performed at $12 \mathrm{~h}$ and $72 \mathrm{~h}$.

Results Clinical characteristics of patients are summarised in the Table 1.

The degree of neonatal encephalopathy was related with CSF-NSE concentrations at $12\left(\mathrm{r}_{\mathrm{s}}=0.38\right)$ but overall at $72 \mathrm{~h}$ of life $\left(r_{\mathrm{s}}=0.83\right)$. aEEG traces at $6 \mathrm{~h}$ but also at $6-12 \mathrm{~h}$ were correlated with CSF-NSE concentration at $12 \mathrm{~h}\left(\mathrm{r}_{\mathrm{s}}=0.544\right.$ and $\left.r_{s}=0.529\right)$ and even more significant at $72 \mathrm{~h}\left(r_{\mathrm{s}}=0.790\right.$ and $r_{\mathrm{s}}$ $=0.768$, respectively).

Conclusions Our study provides additional support about aEEG monitoring during the first $12 \mathrm{~h}$ is a reliable biomarker for early estimates of ongoing brain damage in neonatal HIE.

\section{PO-0451 DEFECTS OF CENTRAL NERVOUS SYSTEM: A REVIEW}

${ }^{1} \mathrm{C}$ Castillo Rukoz, ${ }^{1} \mathrm{M}$ Salamanca Campos, ${ }^{2} \mathrm{~S}$ López Agullo, ${ }^{3} \mathrm{~L}$ Sabonet Morente, ${ }^{1}$ A Sanchis Calvo. ${ }^{1}$ Paediatric, Hospital Universitario Dr Peset, Valencia, Spain; ${ }^{2}$ Pathology Anatomy, Hospital Universitario Dr Peset, Valencia, Spain; ${ }^{3}$ Ginecology, Hospital Universitario Dr Peset, Valencia, Spain

\subsection{6/archdischild-2014-307384.1092}

Background and aims Central nervous system (CNS) appears in the $3 \mathrm{rd}$ week of development, derived from the ectodermal sheet and from the neural plate. The frequency of CNS abnormalities ranges from 0.8 to $1.3 / 100$ live births, and neural tube defects (NTD) are the most common. They are associated with a variety of genetic syndromes, chromosomal abnormalities and a variety of environmental factors.

Methods Retrospective descriptive study by review of medical records of patients diagnosed with CNS malformations in pregnancies controlled on our hospital between 2004-2012.

Results There were 17,759 births, 515 fetuses with birth defects diagnosed prenatally and 114 were CNS defects. In 109 cases an abortion was performed, and 5 live births (acraneo, Dandy Walker, ventriculomegaly, choroid plexus cyst, and a combination). Among the aborted fetuses 49 cases were diagnosed of (NTD), 21 brain defects, 9 midline brain abnormalities, 2 cerebellum defects, and 28 syndromic or multiple malformations. Women with affected fetuses present a mean age of 31.5 years (range 14-44 years), 45 were primiparous. The mean gestational age at the time of abortion was 17 weeks (range 11-29).

Conclusions Of all fetuses aborted with prenatal diagnosis of a congenital defect, CNS abnormalities corresponded to $22.5 \%$. 